\title{
Simulation and Experimentation of Torkbuster Based on ANSYS/LS-DYNA
}

\author{
Hongyan Ma ${ }^{1}$, *, Jingwang Chen ${ }^{1}$, Daning Wang ${ }^{1}$, Shibo Su${ }^{1}$, Xianjing Yang ${ }^{1}$, Xiangzhen Cheng ${ }^{2}$, \\ Xiangjun $\mathbf{Q u}{ }^{1}$ \\ ${ }^{1}$ Directional Drilling Branch, Bohai Drilling Engineering Company, Tianjin, China \\ ${ }^{2}$ Huabei Oilfield Company, Renqiu, China

\section{Email address:} \\ 45274377@qq.com(Hongyan Ma), chenjingwang@cnpc.com.cn(Jingwang Chen),wangdaning19761210@hotmail.com(Daning Wang), \\ 1044172969@qq.com (Shibo Su),529956305@qq.com(Xiajing Yang),kjc_cxz@petrochina.com.cn(XiangzhenCheng), \\ 526911039qq.com(Xiangjun Qu) \\ ${ }^{*}$ Corresponding author
}

\section{To cite this article:}

Hongyan Ma, Jingwang Chen, DaningWang, Shibo Su, Xianjing Yang, Xiangzhen Cheng, Xiangjun Qu. Simulation and Experimentation of Torkbuster Based on ANSYS/LS-DYNA. International Journal of Oil, Gas and Coal Engineering. Vol. 6, No. 4, 2018 , pp. 50-59. doi: 10.11648/j.ogce.20180604.12

Received: June 13, 2018; Accepted: July 5, 2018; Published: July 30, 2018

\begin{abstract}
The stick-slip vibration in deep hard formation is a technical bottleneck restricting the efficient use of PDC bit. In order to combat the stick-slip phenomenon during drilling in deep hard formations, we introduced the high frequency self-excited torkbuster. Based on the analysis of the working principle of the torkbuster, a nonlinear dynamic three-dimensionalmodel of PDC bit is established by using the finite element software (ANSYS/LS-DYNA). The wear conditions and themotioncharacteristicsof the PDC bit as well as the failure of the rock are simulated with and without the action of the high frequency torsional impact, and several field experiments are conducted. The results show that the high frequency torsional impact force generated by the torkbuster can effectively improve the uniformity of the force on the PDC bit and rock, and restrain the stick-slip vibration and the damage of the cutters. The experimental results show that the torkbuster can improve the rock breaking efficiency and shorten the drilling cycle, and provide an important technical reference for the torsional impact technology applying in deep hard formations.
\end{abstract}

Keywords: PDC Bit, Torkbuster, The Finite Element Analysis, Torsional Impact, Stick-Slip Vibration

\section{Introduction}

At present, the development of oil and gas reservoirs in the world has entered the middle and late stages, Thedevelopment proportion of deep wells or ultra-deep wells has gradually increased. However, the failure of PDC bits in deep-hard formations is a technical difficulty faced by fast drilling. When drilling with conventional drill tools, the bit stopped rotating due to insufficient torque after the cutters cut into the hard formation, and then, as the torque continues to increase to a certain value, the front rocksstart to be cut. Meanwhile, the energy stored in the drill strings was suddenly released and the angular velocity of the drill bit was increased several times. At this time, the drill bit was in a slip state. After that, it goes back to the stick stage again. During the drilling process, the drill bit is always in a periodic stick-slip stage alternately, Each time the stick-slip state changes, it may cause the lateral, longitudinal and coupling vibration of the drill strings, whichincreases the fatigue failure of the drill string (MWD, shock absorber, etc.) and drill bit. In order to reduce the stick-slip vibration and failure of PDC bit in the drilling process [1-6], a new type of self-excited high-frequency torkbuster (abbreviated as torkbuster) was introduced. Through theoretical analysis, simulation and field tests, it was found that the rock breaking mechanism of PDC bit with and without torkbuster is different, and it has obvious effect on ROP improvement [7-10].

\section{Working Principle and Rock Breaking Mechanism of Torkbuster}

Tool structure: The torkbuster mainly relies on the hydrau- 
lic difference formed by the drilling fluid in the impact chamber to drive the impact hammer to generate a circumferential rotating impact. It is composed of drilling fluid circulation starting mechanism (guide cavity, variable flow nozzle), impact mechanism (impact hammer, impact cavity), torque transmission mechanism and so on. See Figure 1, 2.

The diverter divides the drilling fluid into two parts, one part is provided to the variable flow nozzle, and the other part flows out directly from the drill bit; the sub body connected with the transmission joint through gap and positioned by spline. The impact mechanism consisting of impact hammer and impact chamber is fixed on the transmission joint through 6 prisms to provide circumferential power to the drill bit.

Working principle: the drilling fluid flows into the diverter during work, Part of it flows through the variable flow nozzle and the guiding cavity to make the impact chamber form a high pressure zone to drive the impact hammer to twist and impact the impact chamber, and the torque transmission mechanism obtains energy to complete a forward impact. Andthen, the second high-pressure zoneformed bychangingthe flow direction ofthe drilling fluid through the variable flow nozzle and the guiding cavity drives the impact hammer to rotate reversely [11]. The periodic forward and reverse rotation will transfer the generated energy to the drill bit through the torque transmission mechanism, so that the drill bit can obtain high frequency and stable torsional force. The relevant working parameters are shown in Table 1:

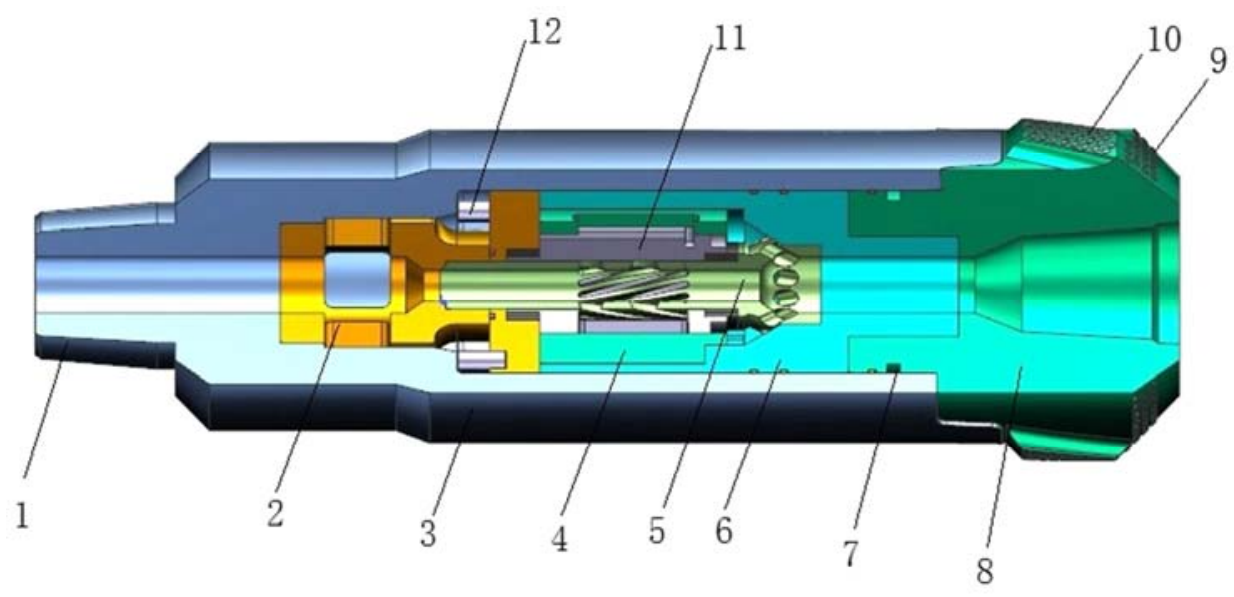

Figure 1. Structure diagram of self-exciting torkbuster.

1. pin; 2. diverter; 3. sub body; 4. impact hammer; 5. screen tube; 6. impact chamber; 7. sealing ring; 8. transmission joint(REG internal thread); 9. hard alloy protective block; 10 . hard alloy gauge block 11 . circulation starting mechanism; 12 . limit pin.

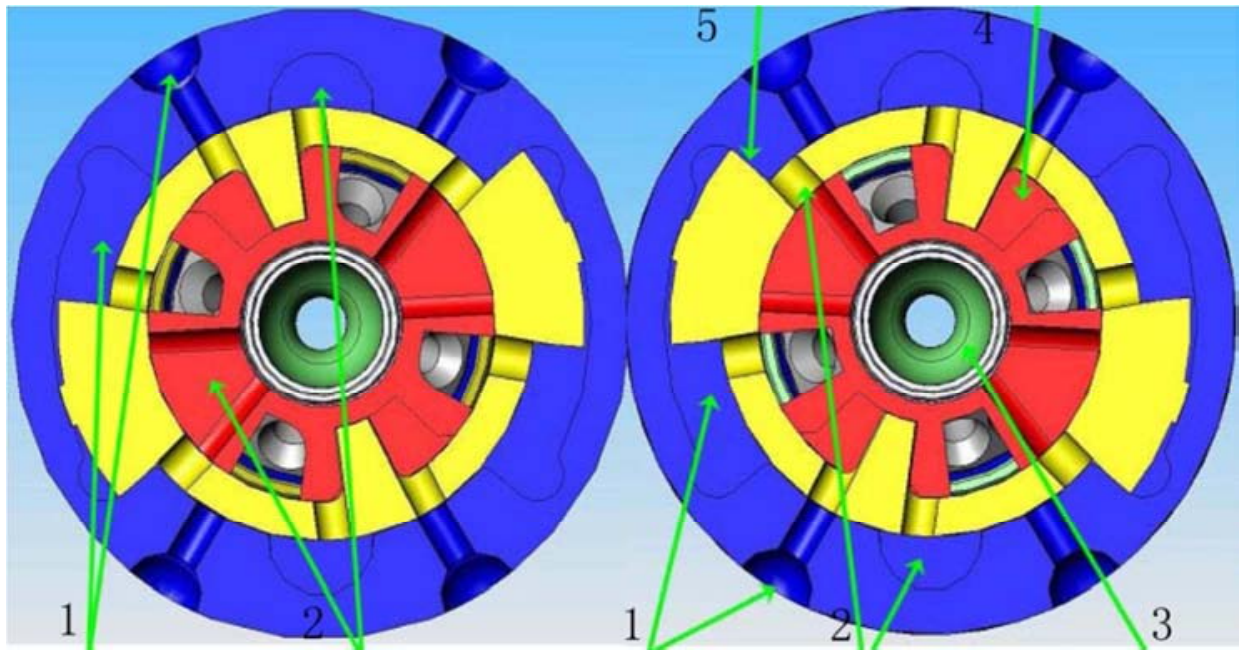

1. low pressure zone; 2 . high pressure zone; 3. variable flow nozzle; 4. guide cavity; 5. Impact plane.

Figure 2. Working schematic diagram of the hydraulic impact hammer in forward and reverse direction

Rock breaking mechanism: When the PDC bit is used in conjunction with a torkbuster, the bit is subjected to a total of 3 forces1) The axial force from the drill string (WOB), 1) The axial force from the drill string (WOB), 2) the torque provided by the rig, 3) the torque provided by the torkbuster. When drilling, the drill bit impacts the rock and rotates under the three forces. the high frequency and continuous shear forces generated by torkbuster directly transferenergy to thedrill bit withoutwaiting for the drill string torque to accumulate. Theenergyprovided to the entire drill string iscompletelyused 
to shear the rock, and the torque is always stable and balanced [12]. As a result, the stick-slip vibration of the drill bit is greatly reduced, the life of the drill bit is prolonged, the fatigue effect on the drill string is reduced, and the drilling efficiency is improved.

Table 1. Working parameters of torkbuster.

\begin{tabular}{|c|c|c|c|c|c|c|c|}
\hline structure & Impact frequency & $\begin{array}{l}\text { torsional } \\
\text { force }\end{array}$ & $\begin{array}{l}\text { Working } \\
\text { capacity }\end{array}$ & $\begin{array}{l}\text { Pressure } \\
\text { drop }\end{array}$ & $\begin{array}{l}\text { Maximum } \\
\text { temperature }\end{array}$ & $\begin{array}{l}\text { Maximum } \\
\text { WOB }\end{array}$ & operating hours \\
\hline Pure machinery & $1000-2000 \mathrm{~Hz} / \mathrm{min}$ & 2000N.m & $25-33 \mathrm{~L} / \mathrm{S}$ & $2-2.5 \mathrm{Mpa}$ & $300^{\circ}$ & $120 \mathrm{KN}$ & $300 \mathrm{~h}$ \\
\hline
\end{tabular}

\section{Modeling}

In order to simulate the wear condition of the bit and the failure of the rock with and without the action of torkbuster, the universal display dynamic finite element analysis software (LS-DYNA) was used. The software can be used in conjunction with ANSYS to perform analysis of various nonlinear transient dynamic processes. According to the content of the study to improve accuracy, ignore the secondary factors, and make the following assumptions [13-14]:

1. Rocks are continuous, uniform, and isotropic media. Does not considerthe effect of the drilling fluid and temperature on the rock.

2. The PDC bit is a rigid body and the cutters are composite sheets, which have greater hardness and strength than rocks.

3 . The broken rock elements are automatically removed and the impact of subsequent rock breaking processes is not considered.

4. The surrounding and bottom of the rock model belongs to the far field part of the borehole.

\subsection{Definition of Element Type}

Both the rock and drill bit in the model use a three-dimensional explicit structural solid element SOLID164 The element has 8 nodes, which have the freedom of translation, velocity, and acceleration in the $\mathrm{X}, \mathrm{Y}$, and $\mathrm{Z}$ directions. The tetrahedron generated when defined the same node number $(\mathrm{M}, \mathrm{N}, \mathrm{O}, \mathrm{P}$, and $\mathrm{K}, \mathrm{L})$ is applied to the mesh division. As shown in Figure 3.

\subsection{Model Material Definition}

The rock material adopts the hard rock formation of tight sandstone with a relatively uniform composition, and it is assumed that the rock is brittle during the simulation. The material properties of the drill bit are replaced with PDC composite sheet material. The drill pipe is the ordinary rigid material and does not limit the simulation parameters. Simulation material parameters are shown in Table 2.
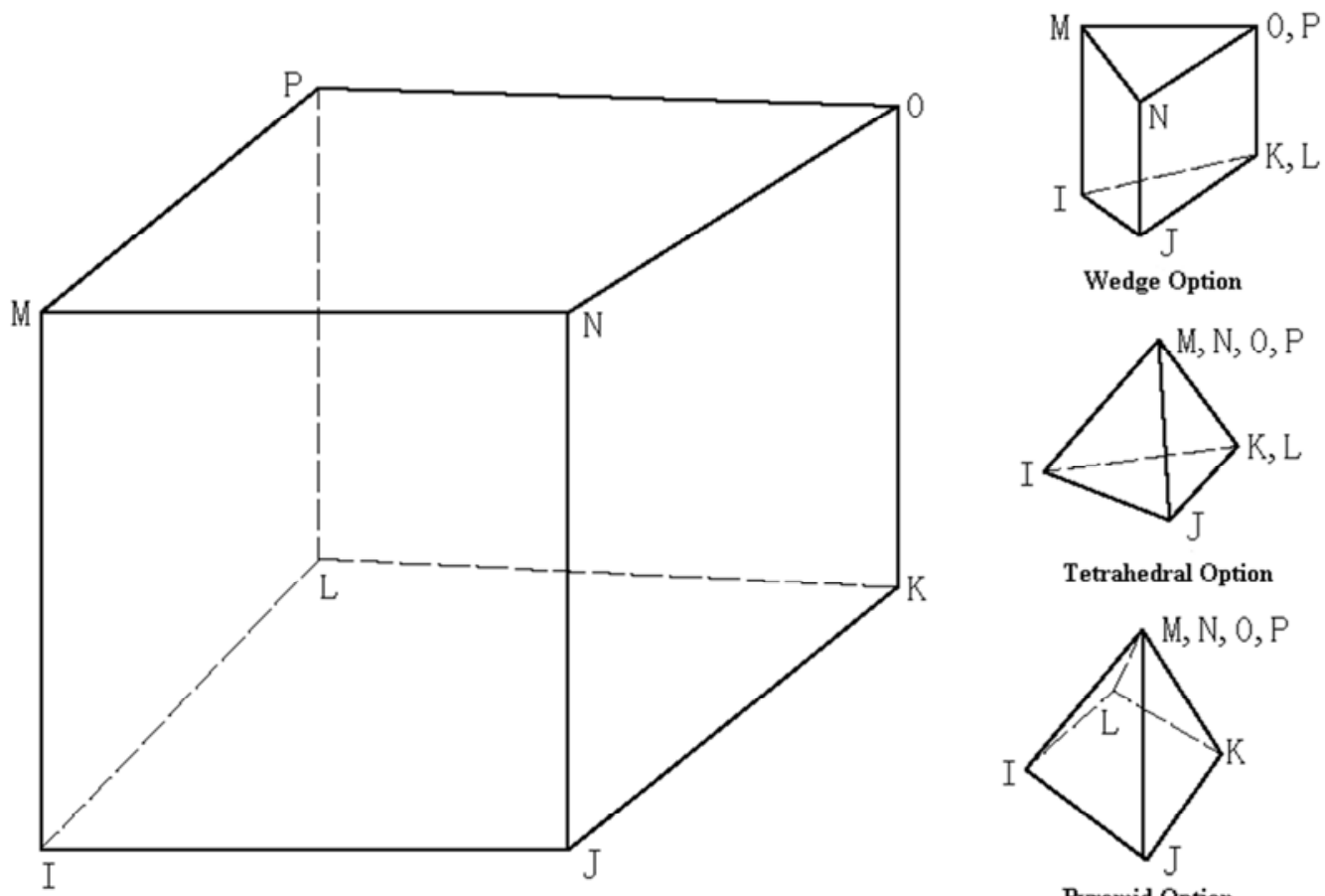

Tetrahedral Option

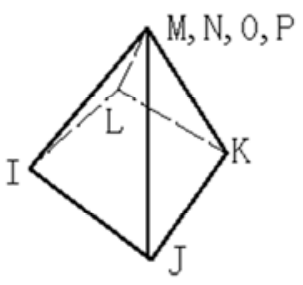

Pyramid Option

Figure 3. The element figure of solid164.

Table 2. The parameters of material used for simulation.

\begin{tabular}{|c|c|c|c|c|}
\hline & Densityg/ $/ \mathrm{cm}^{3}$ & Elastic ModulusMp & Poisson's ratio & Coefficient of friction \\
\hline rock & 2.84 & 43080 & 0.19 & 0.25 \\
\hline Drill bit & 4.42 & 810000 & 0.07 & 0.25 \\
\hline
\end{tabular}




\subsection{Establishment of Solid Model and Mesh Division}

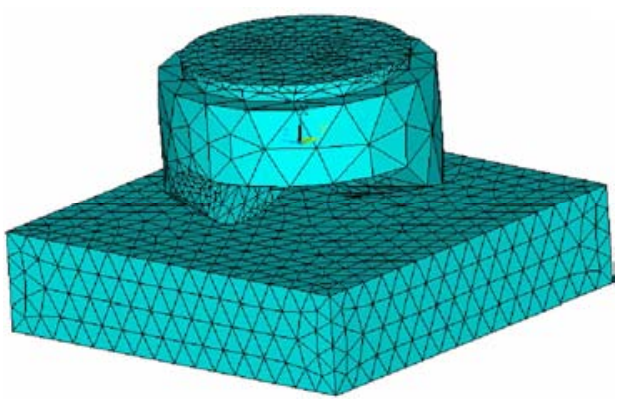

Figure 4. Finite element model of PDC bit and rock.

The model is divided into rock section and drill bit section, where the rock model is represented by cuboid. The drill bit model is a PDC bit with two cutters, the cylindrical part above the drill bit represents the drill string and provides drilling parameters such as torque and WOB. Rock size: $100 * 100 * 40 \mathrm{~mm}$, drill bit size: Outer diameter $60 \mathrm{~mm}$, tooth height $10 \mathrm{~mm}$. Select the cell with length of 2 to uniformly divide it into tetrahedral meshes, and refine the drill bit to improve the calculation accuracy [15]. (See Figure 4) According to rock breaking characteristics of the PDC cutters, the contact algorithm between the cutters and the rock surface uses the erosion contact algorithm among the surface-surface contact provided by the LS-DYNA program. It can simulate material failure during the drilling process and automatically remove the failed element, where the drill bit is the target surface and the rock formation is the contact surface.

\subsection{Loading Constraints}

Limits the translation and rotation of the cutters reference point on the $\mathrm{X}$ and $\mathrm{Y}$ axes, defines the displacement and torque of the cutters reference point on the $\mathrm{Z}$ axis. According to the effect of the impact on the PDC cutters, the original load number is maintained when the torkbuster is used, a torsional impact load is applied to the cutting tooth reference point as the periodic pulse. During simulation, the Drucker-Prager criterion was used as the criterion for rock strength. Drilling simulation parameters are shown as below(Table 3 ).

\section{Simulation Analysis}

Perform numerical simulationstothe rock breaking processes and drill bit damages under bothconventional drilling and high frequency torsional impact conditions. Extract simulation results under the two different conditions. Analyze the rock opening shape, drill bit damage and drill bit movement characteristics.

Table 3. Drilling simulation parameters.

\begin{tabular}{lllll}
\hline WOBKN & TorqueN.m & Impact torqueN.m & Impact timeS & Impact frequency (N/min) \\
\hline 120 & 6500 & 1600 & 0.002 & 1300 \\
\hline
\end{tabular}

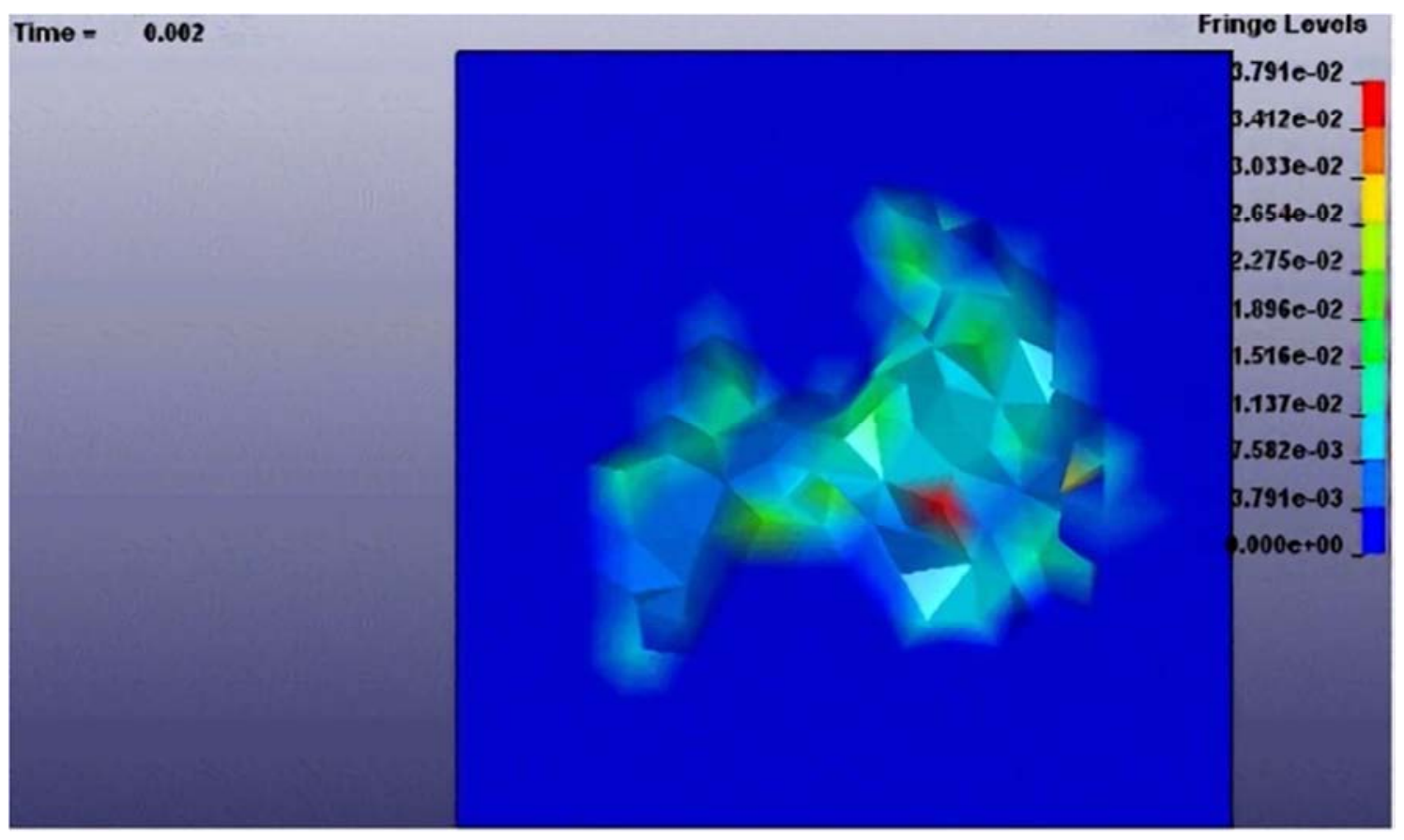

Figure 5. Displacement nephogram of the rock break for Conventional drilling.

\subsection{Rock Opening Shape Analysis}

Figure 5 and Figure 6 show the displacement neph- ogram of rock opening shape under the two different conditions. It can be seen from Figure 5 that the rock opening shape under conventional drilling is asymmetrical, and part of the rock- 
sarenot removed. While figure 6 shows the rock opening shape under high-frequency torsional impact is close to a circle, the opening area is larger than that of conventional drilling, and the rock breaks evenly. It shows that under the same drilling parameters, the high-frequency torsional impact can improve bit's cutting efficiency, increase the impact force on rock, and enhancebit'sstability in the formation.

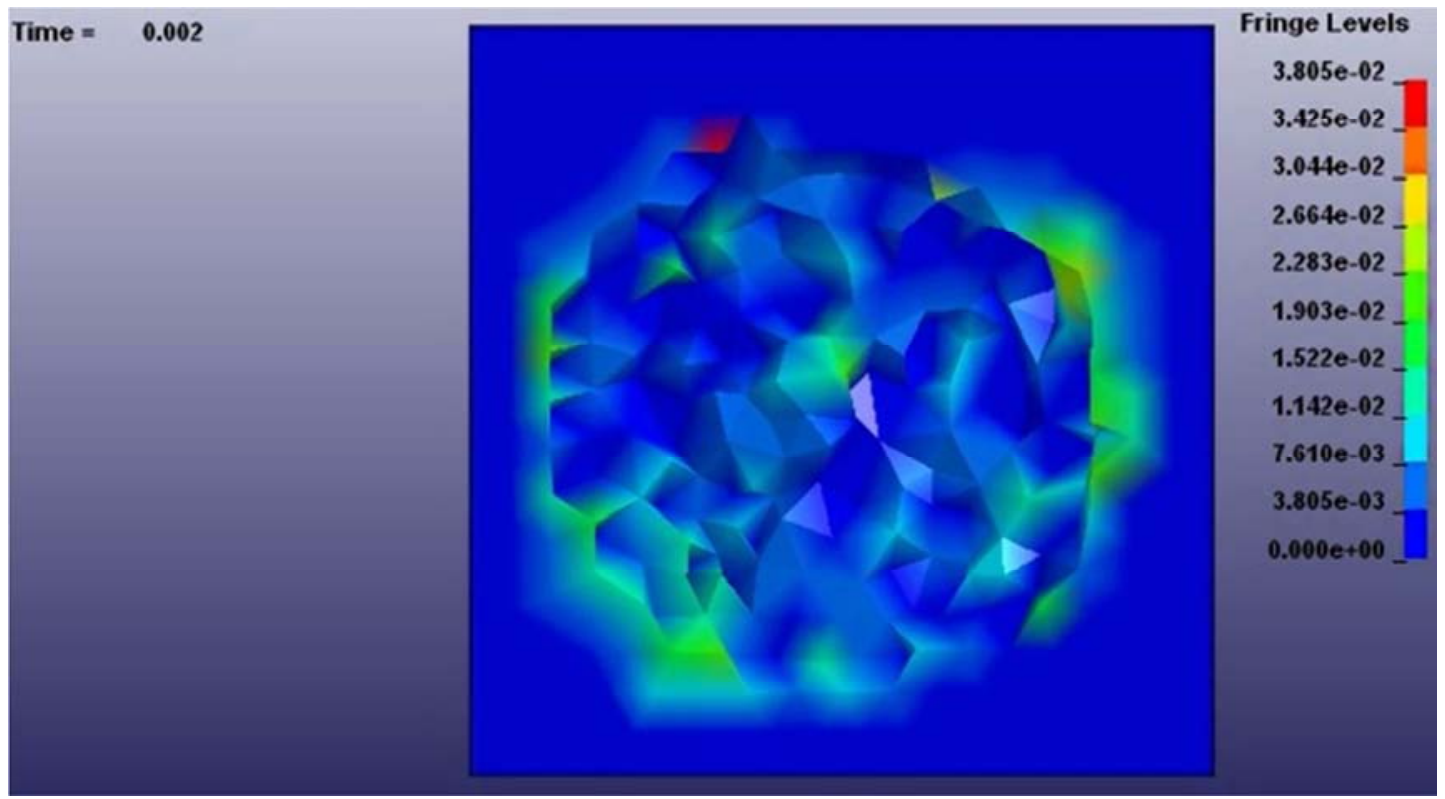

Figure 6. Displacement nephogram of the rock break forhigh frequency torsional impact.

\subsection{Comparison of Bit Motion}

The Displacement nephogram of PDC bitin $0.001 \mathrm{~s}$ and $0.002 \mathrm{~s}$ underbothconventional drilling and high frequency torsional impact drilling were extracted respectively. Figure 7 shows displacement nephogram of PDC bit under conventional drilling, While figure 8 shows displacement nephogram of PDC bit under high frequency torsional impact.

It can be seen from Figure 7 that serious displacements have occurred in various parts of the outer contour of the drill bit, and the upper and lower parts of the surface have been tilted. It shows that the bit is notevenly loaded. If the non-uniform force is applied for a long time, stress concentration occurs in a part of the cutting teeth and causes premature damage.

However, when the drill bit is subjected to high-frequencytorsional impact (Figure 8), the surface of the drill bit basically coincides without serious tilt, the bit is in good working condition and can effectively avoid to damage.

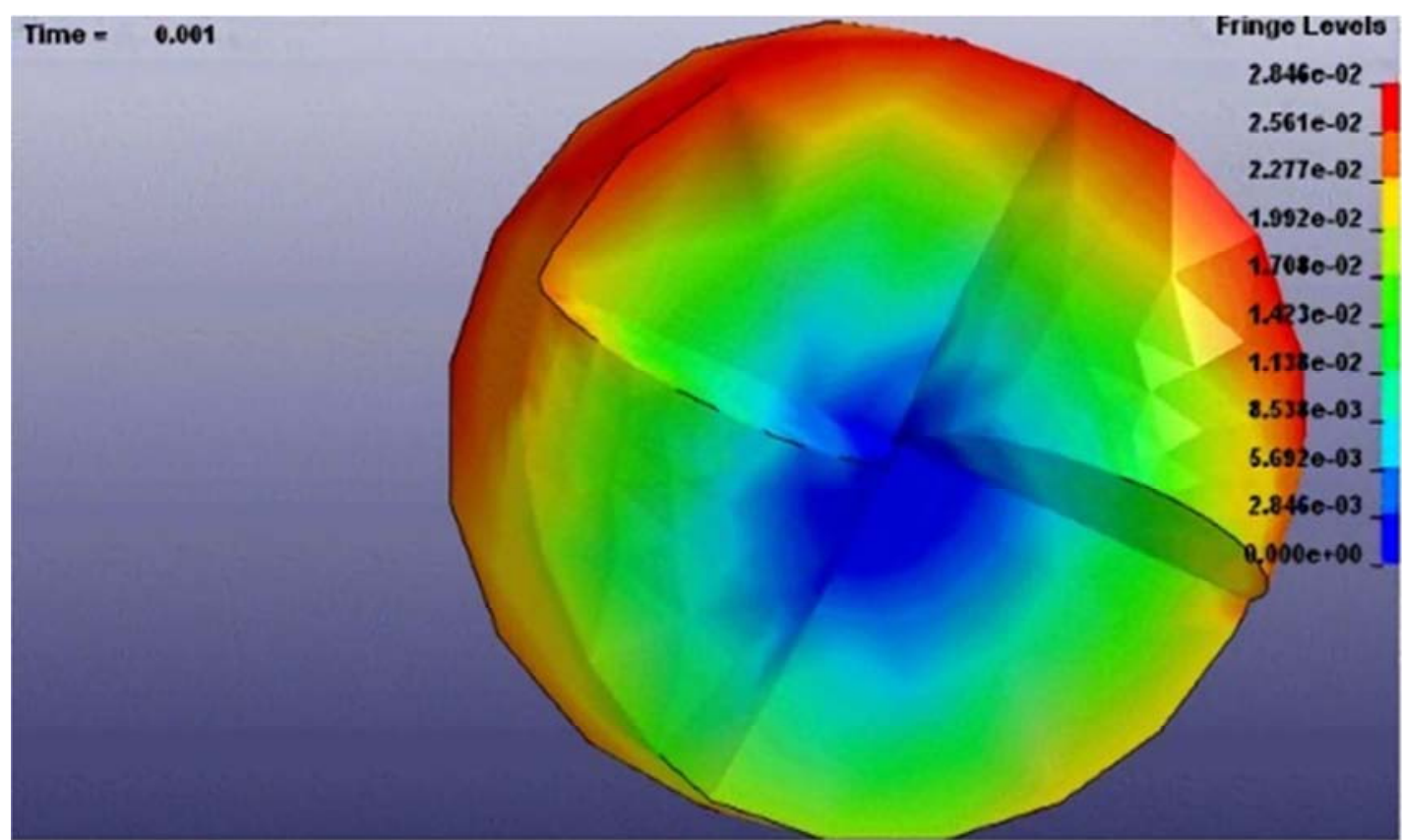

(a) 


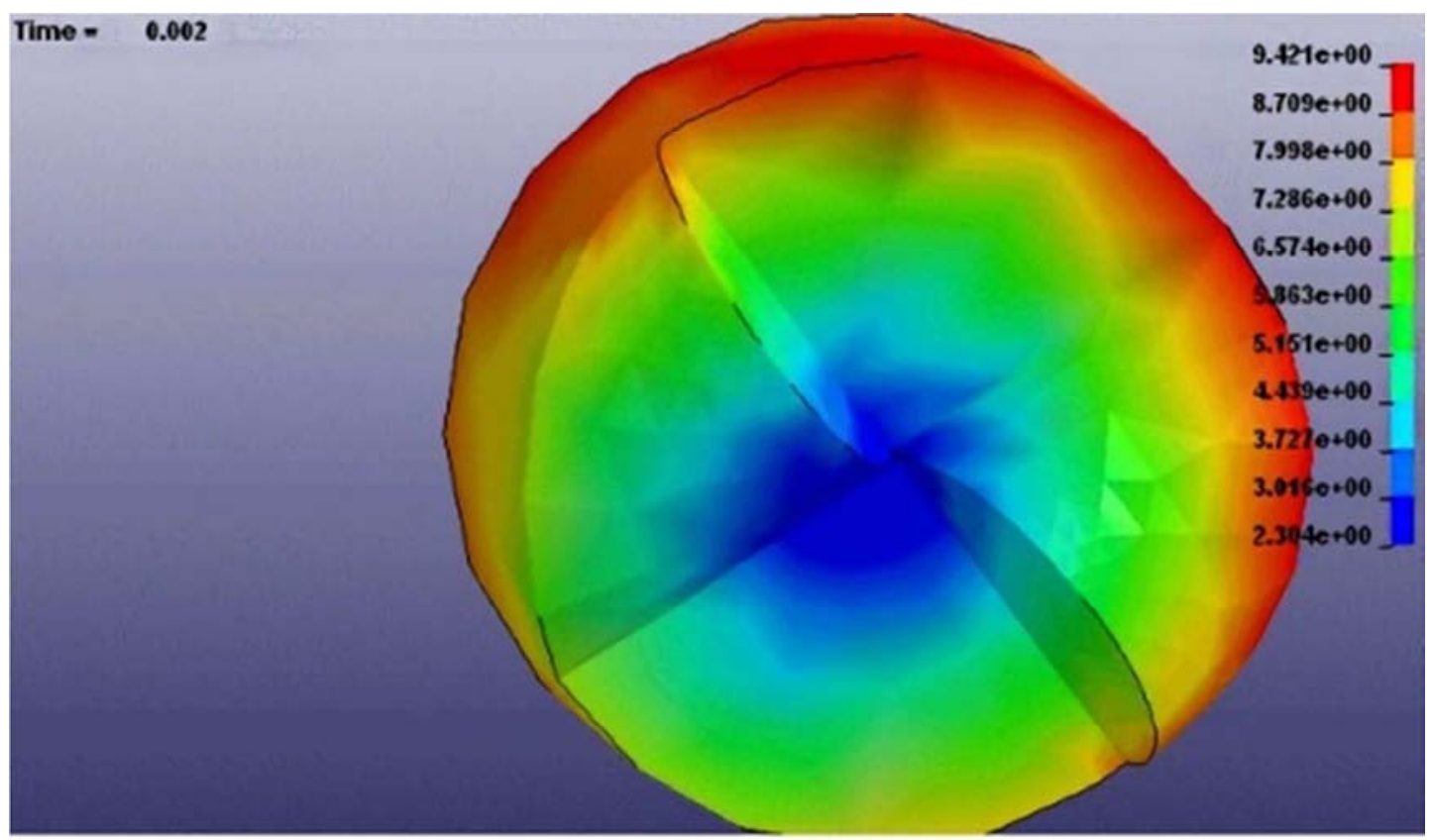

(b)

Figure 7. Displacement nephogram of PDC bitfor conventional drilling. (a) $0.001 \mathrm{~s}$, and (b) $0.002 \mathrm{~s}$.

\subsection{Analysis of Drill Bit Motion Characteristics}

The torque variation curve (Figure 9) and the angular velocity variation curve (Figure 10) of the bit motion within 20s during drilling with or without tors--ional impact were extracted.

As shown in Figure 9, at the beginning of the drilling stage, the torque gradually increases and the amplitude changes little as the drill bit just touches the surface of the rock. For conventional drilling, after the cutters of bit completely entering the rock, the torque increases rapidlyas the resistance put on bit increases, which indicates that the cutting force generated by the bit is not enough to break the rock and it is in a stickphase. And then rock was broken and the energy stored in drill string was released rapidly, the drill bit changes to be in a slip phase due to a sudden reduction in torque. Theperiodic high torque changes shorten the life of the cutters. While for high frequency torsional impact drilling, although there is a periodic change in bit torque, the magnitude of torque fluctuation is much smaller than conventional drilling. Therefore, the stick-slip vibration of the drill bit is reduced, and the protection to the cutters is improved.

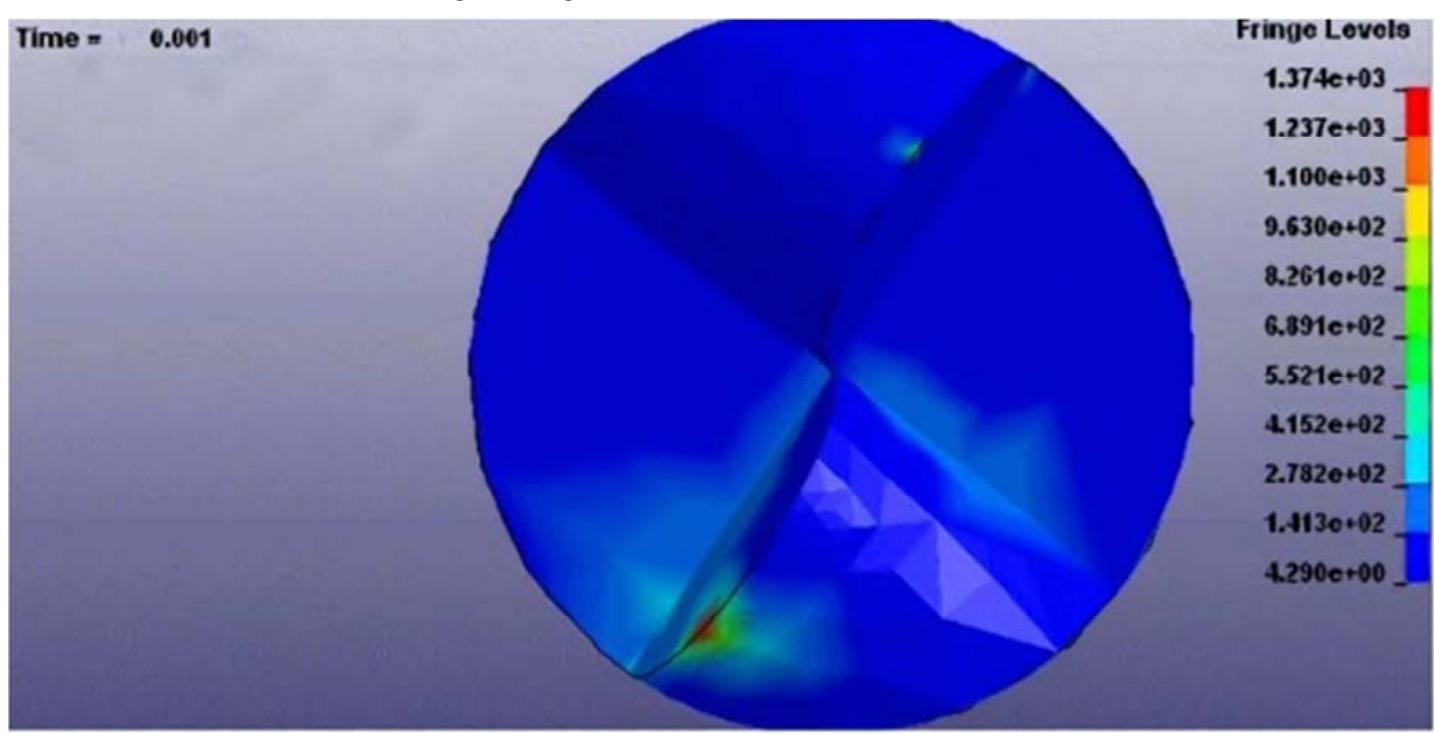

(a) 


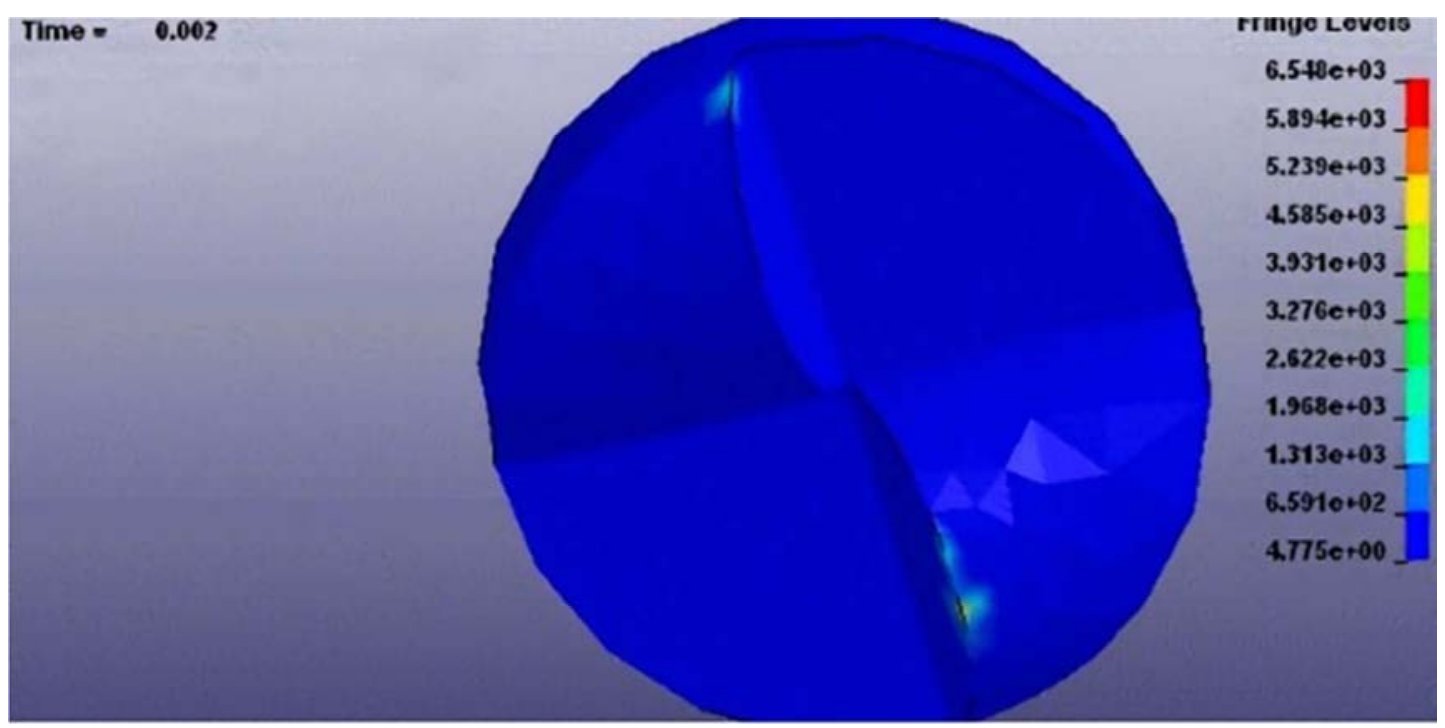

(b)

Figure 8. Displacement nephogram of PDC bitfor high frequency torsional impact. (a) 0.001 , and (b) $0.002 \mathrm{~s}$.

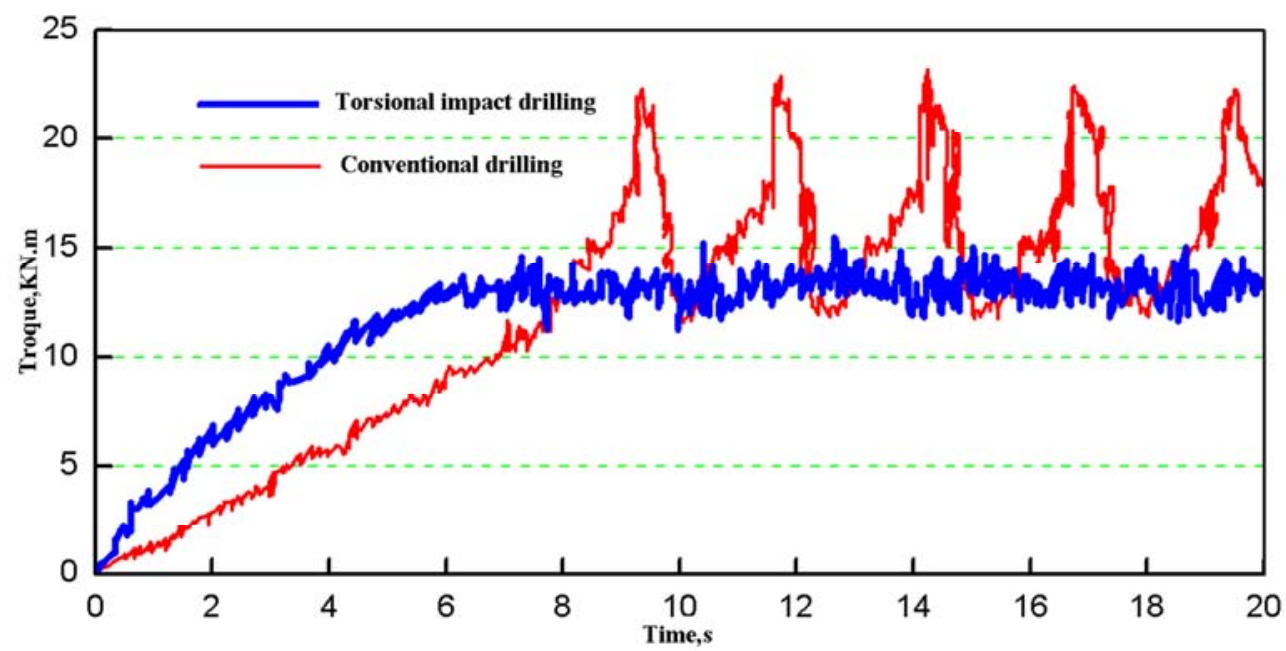

Figure 9. The bit torque curve of different drilling types.

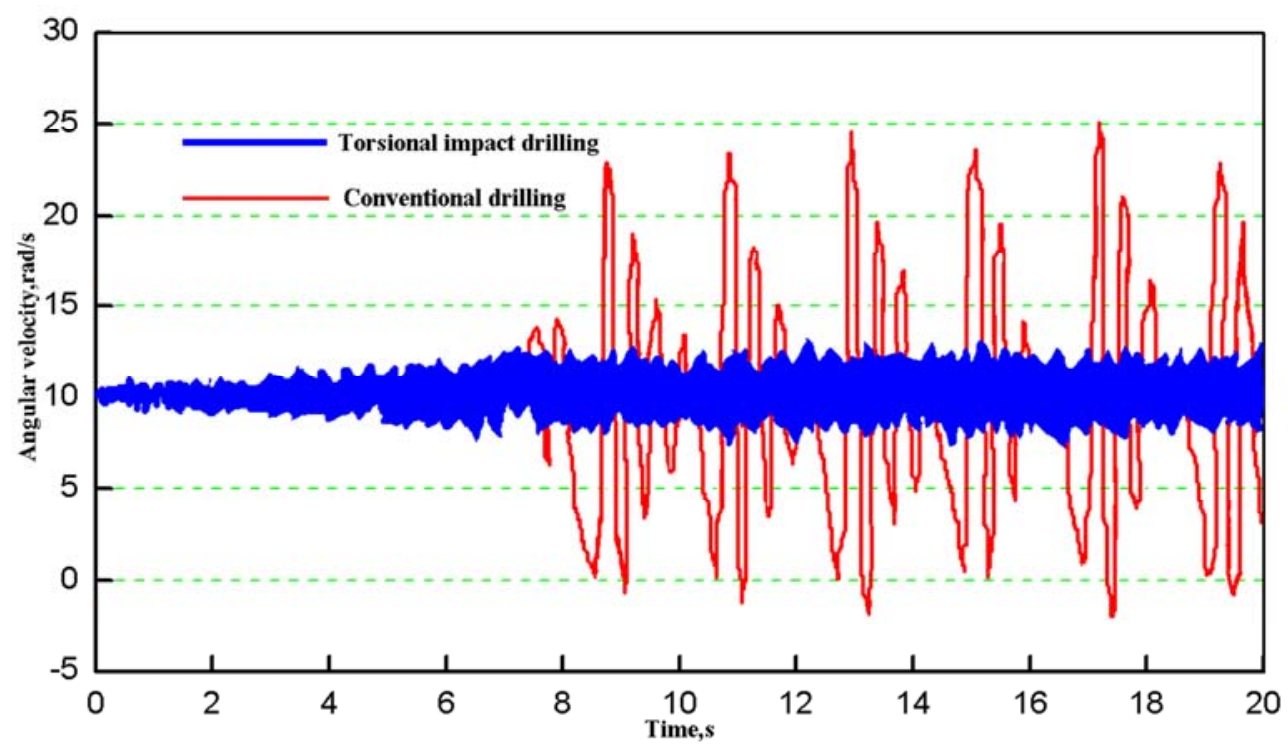

Figure 10. The bit angular velocity curveof different drilling types. 
Table 4. The ROP on different drilling types.

\begin{tabular}{llllll}
\hline Well NO. & Experimental section $(\mathbf{m})$ & Inclination change $\left.\mathbf{(}^{\circ}\right)$ & drilling time $(\mathbf{h})$ & $\mathbf{R O P}(\mathbf{m} / \mathbf{h})$ & Note \\
\hline Mo31-25x & $2905-2603$ & $23.13-1.15$ & 135 & 5.47 & Bit + Torkbuster \\
Mo31-15x & $2970-3643$ & $19.32-1.13$ & 120 & 5.60 & Bit + mud motor \\
Mo31-19x & $2891-3579$ & $13.16-2.95$ & 123 & 5.59 & Bit + Torkbuster \\
Mo31-28x & $3118-3743$ & $28.71-6$ & 201 & 3.11 & Bit + Regular BHA \\
Mo31-30x & $2918-3647$ & $19-13.5$ & 144 & 5.06 & Bit +mud motor \\
Su20-24-9X & $2092-3720$ & $11.35-0.47$ & 251 & 6.48 & Bit+Regular BHA \\
Su20-24-15X & $2923-3756$ & $10.05-1.68$ & 70 & 11.90 & Bit + Torkbuster \\
Su20-24-16X & $2877-3711$ & $10.21-1.35$ & 129 & 6.46 & Bit +Regular BHA \\
Su20-24-10X & $2903-3580$ & $0.66-0.4$ & 77 & 8.35 & Bit +mud motor \\
\hline
\end{tabular}

Figure 10 shows the bit angular velocity curve on different drilling types. It can be seen from the figure that the angular velocity fluctuates during conventional drilling and high frequency torsional impact drilling. However, during conventional drilling, the lower drill strings gradually stop rotating due to insufficient rock stage and the angular velocity is close to zero. When the energy is accumulated to the rock breaking limit, it suddenly releases, the drill bit rotates at high speed, and the angular velocity reaches maximum. Each time the stick-slip occurs, the lower drill string accelerates to rotate several times in the forward and reverse directions to cause the cutters to break or the drill string to fail prematurely. The amplitude of angular velocity fluctuations during high frequency torsional impact drilling is significantly reduced. The energy from thedrill string is fully utilized to break the rock, improving the efficiency of bit.

Table 5. ROP comparison of torkbuster for AT1 and AT4 wells.

\begin{tabular}{|c|c|c|c|c|c|c|c|c|c|c|c|}
\hline $\begin{array}{l}\text { Well } \\
\text { NO. }\end{array}$ & $\begin{array}{l}\text { Interval } \\
\text { (m) }\end{array}$ & Tool & Bit model & Lithology & $\begin{array}{l}\text { interval } \\
\text { Length } \\
\text { (m) }\end{array}$ & $\begin{array}{l}\text { Slide } \\
\text { foot- } \\
\text { age(m) }\end{array}$ & $\begin{array}{l}\text { Slidetime } \\
\text { (h) }\end{array}$ & $\begin{array}{l}\text { slideRop } \\
(\mathbf{m} / \mathbf{h})\end{array}$ & $\begin{array}{l}\text { Rotary } \\
\text { footage } \\
(\mathrm{m})\end{array}$ & $\begin{array}{l}\text { Rotary } \\
\text { time } \\
\text { (h) }\end{array}$ & $\begin{array}{l}\text { Rotary } \\
\text { Rop } \\
(\mathbf{m} / \mathbf{h}) \\
\end{array}$ \\
\hline \multirow{12}{*}{ AT1 } & \multirow{3}{*}{$4158 \sim 4213$} & \multirow{3}{*}{$\begin{array}{l}\text { Mud } \\
\text { motor }\end{array}$} & \multirow{3}{*}{$\begin{array}{l}\text { Best } \\
\text { T1655AUG }\end{array}$} & sandstone & 13 & 1 & 1 & 1 & 13 & 3.46 & 3.76 \\
\hline & & & & Mudstone & 34 & / & l & l & 34 & 28.25 & 1.20 \\
\hline & & & & Pebbly sandstone & 9 & / & l & l & 9 & 6.60 & 1.36 \\
\hline & \multirow{3}{*}{$4213 \sim 4291$} & \multirow{3}{*}{$\begin{array}{l}\text { Tork } \\
\text { buster }\end{array}$} & \multirow{3}{*}{$\begin{array}{l}\text { Best } \\
\text { M1365DG }\end{array}$} & sandstone & 17 & / & l & l & 17 & 4.21 & 4.04 \\
\hline & & & & Mudstone & 54 & / & l & l & 54 & 20.45 & 2.64 \\
\hline & & & & Fine conglomerate & 7 & l & l & l & 7 & 2.39 & 2.93 \\
\hline & \multirow{4}{*}{$4291 \sim 4380$} & \multirow{4}{*}{$\begin{array}{l}\text { Mud } \\
\text { motor }\end{array}$} & \multirow{4}{*}{$\begin{array}{l}\text { Best } \\
\text { M1365DG }\end{array}$} & sandstone & 6 & / & l & l & 6 & 1.03 & 5.83 \\
\hline & & & & Mudstone & 21 & 6 & 2.67 & 2.25 & 15 & 5.30 & 2.83 \\
\hline & & & & conglomerate & 57 & 14 & 7.77 & 1.80 & 43 & 14.40 & 2.99 \\
\hline & & & & Basalt & 5 & / & l & l & 5 & 2.58 & 1.94 \\
\hline & \multirow{2}{*}{$4380 \sim 4444$} & \multirow{2}{*}{$\begin{array}{l}\text { Tork } \\
\text { buster }\end{array}$} & Best & Mudstone & 1 & / & l & l & 1 & 0.92 & 1.08 \\
\hline & & & M1365DG & conglomerate & 63 & / & l & l & 63 & 56.33 & 1.12 \\
\hline \multirow{6}{*}{ AT4 } & \multirow[t]{2}{*}{$4098 \sim 4202$} & \multirow{2}{*}{$\begin{array}{l}\text { Mud } \\
\text { motor }\end{array}$} & \multirow{2}{*}{$\begin{array}{l}\text { Best } \\
\text { T1655AUG }\end{array}$} & Mudstone & 49 & 9 & 4.66 & 1.93 & 40 & 18.96 & 2.11 \\
\hline & & & & Pebbly sandstone & 13 & / & l & l & 13 & 6.40 & 2.03 \\
\hline & \multirow{4}{*}{$4202 \sim 4480$} & \multirow{4}{*}{$\begin{array}{l}\text { Tork } \\
\text { buster }\end{array}$} & \multirow{4}{*}{$\begin{array}{l}\text { Best } \\
\text { T1665B }\end{array}$} & sandstone & 91 & & & & 91 & 27.88 & 3.26 \\
\hline & & & & Mudstone & 116 & & & & 116 & 42.65 & 2.72 \\
\hline & & & & conglomerate & 67 & & & & 67 & 22.26 & 3.01 \\
\hline & & & & Basalt & 4 & & & & 4 & 2.14 & 1.87 \\
\hline
\end{tabular}
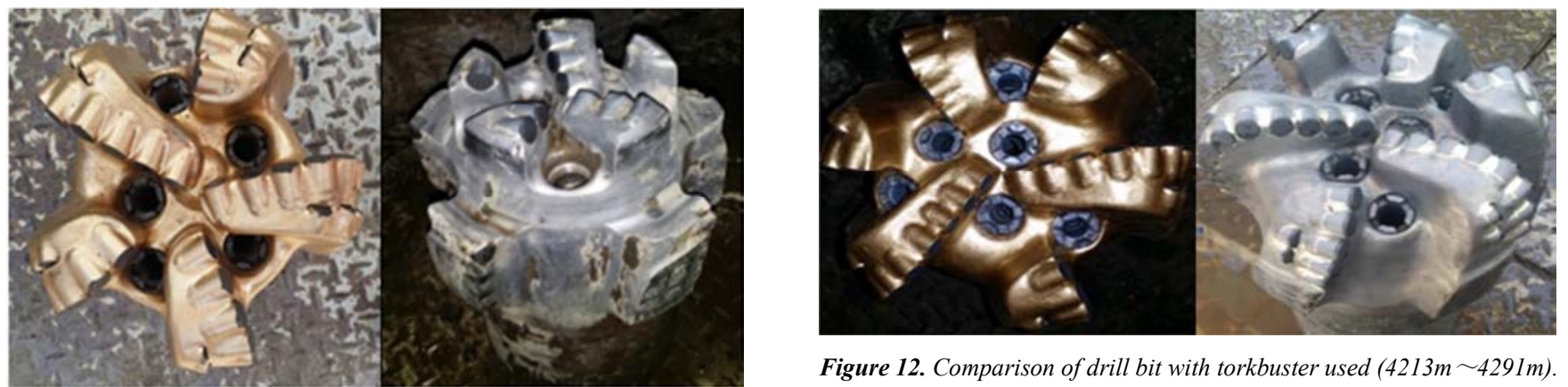

Figure 11. Comparison of drill bit with mud motor used $(4158 \mathrm{~m} \sim 4213 \mathrm{~m})$.

Figure 12. Comparison of drill bit with torkbuster used (4213m $\sim 4291 \mathrm{~m})$ 


\section{Field Experiment}

Torkbuster were used for field tests in blocks of different oil fields [16-18]. For 8 wells such as Kong 8 well, Kong 7 well and Kong 11 well in Dagang District, the total footage is 7567 meters and the overall ROP is rised by $35 \%$. The maximum footage of a single run was 1,581 meters. And the maximum cumulative downhole time is 360 hours. The Yaxi 102 well in the Yumen Oilfield has created the highest record with ROP $3.97 \mathrm{~m} / \mathrm{h}$ [19]. In the Sulige and Jizhong districts, the hold section and the drop section of the five-stage (S type) well use torkbuster to compare the ROP. See Table 4.

From the field test data in Table 4, it can be seen that the ROPwhentorkbuster used is slightly higher than that of mud motor used, but it is 2 to 3 times higher than that of regular BHA used.

The comparison of the effect of torkbuster used in the AT1 well and AT4 well of the Yangshuiwu Buried hill clusters in the Langgu Depression is shown in Table 5.

From the field experimental data in Table 5, it is found that: 1) In the interval $4158 \mathrm{~m}$ to $4291 \mathrm{~m}$, rotary drilling is adopted at the same time, and the ROP of torkbuster used is 1 to 2 times higher than that of mud motor used. The comparison of the bit damage before and after run in hole is shown in Figures 11 and 12. From the comparison chart, it can be seen that mud motorare used in the sandy mudstone layer containing conglomerate and serious wear on the bit shoulders happens after $\mathrm{POOH}$, the wearing part is $142 \mathrm{~mm}$ in diameter. However, the drill bit when torkbuster used has little wear and good integrity. 2) Two different tools are used in the interval $4291 \mathrm{~m}$ to $4444 \mathrm{~m}$ The comparison of the bit damage before and after drilling is shown in Figures 13 and 14. It can be seen from Table 5 that the ROP with mud motor used is higherthan that of torkbuster used. However, the central part ofdrill bit with mud motor used was completely worn out after $\mathrm{POOH}$, whilethe drill bit with torkbuster used has very little damage. It is indicated that torkbuster used in the conglomerate and basalt formations can well protectthe cutters, which is consistent with the simulation results. 3) Two different tools are used in the interval from $4098 \mathrm{~m}$ to $4480 \mathrm{~m}$ of the AT4 well, The ROP is close to that of the AT1 well, and the bit damage after $\mathrm{POOH}$ is similar to that of the AT1. However, the cost of using torkbuster is lower than that of mud motor, and the protective effect to the drill bit is higher than that of mud motor.

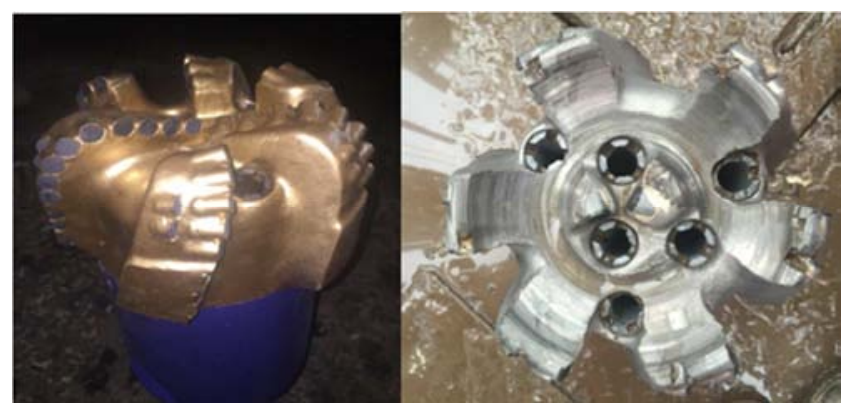

Figure 13. Comparison of drill bit with mud motor used (4291m $\sim 4380 \mathrm{~m})$.

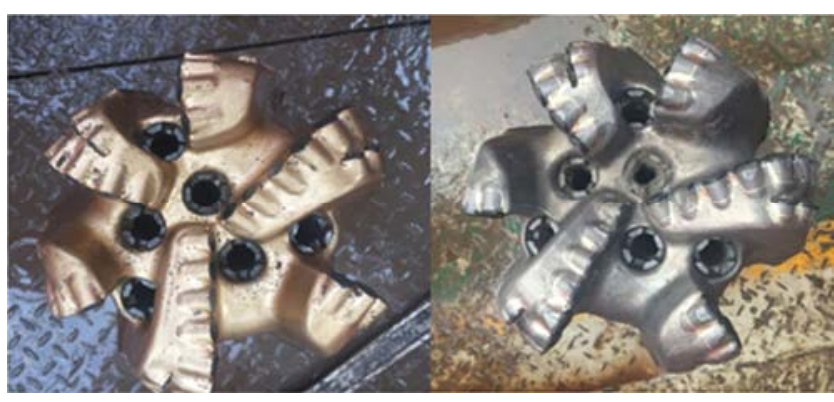

Figure 14. Comparison of drill bit with torkbuster used (4380m $4444 \mathrm{~m})$.

\section{Conclusion and Suggestion}

Through the analysis to the working principle of the self-excited torkbuster, establishmentof the finite element model, simulation of the PDC bit damage and rock breaking mechanism with or without torkbusterand the field experiment there sulte shows that: The pure mechanical structure of torkbuster increases the energy efficiency because that high-frequency torsional impact force generated by the drilling fluid during work is completely applied to the drill bit. Under high frequency torsional impact, the PDC bit works stably, the cutting teeth are evenly forced and the rock breaking isregular. After the drill bit completely entering the formation, the fluctuations of torque and angular velocity are reduced, the life of the drill bit and the rock breaking efficiency are improved, and the "stick-slip vibration" suffered by the drill bit is well suppressed.

It has provided a new method for the hold and drop section of the five-stage wells in the Sulige and Suligedistrictstospeed up. In the deep-hard formations of the Dagang and Yumen oil fields, the use of torkbuster has significantly increased the ROP. It can shorten the cycle and reduce the input cost of mud motor and drilling fluid. In addition, the use of torkbuster in conglomerate or basalt formations can provide good protection for the drill bit. However, when install itbetween the drill bit and mud motor in the field, the build up rate can not meet the trajectory design requirements, it is recommended to improve the compatibility with the mud motor to play a greater role.

\section{Acknowledgements}

This research was supported by the China NationalPetroleum Corporation's major scientific and technological project (2017E-15),(2014E-35)and Bohai Drilling Engineering Company of China Petroleum's Project (2012ZD17Y) for which the authors express their appreciation.

\section{References}

[1] J. Yang, Research and application of PDC drill bit vibration assisted rock tools. WuHan: School of Petroleum Engineering Yangtze University, 2014.

[2] W. Li, X. P. He, T. Yan and S. C. Wang, Rock fragmentation mechanism and application of near-bit torsion impacter, Oil drilling \& production technology, 2014, 36(5):1-4. 
[3] X. Chen, S. Y. Chen, C. Wang and R. Y. Rui, Application of TorkBuster to sidetracking of slimhole horizontal well in Well Songshen 9H.Oil drilling \& production technology, 2014, $34(2): 32-35$

[4] H. W. Zhang and Y. J. Ma, Analysis and Study on Application of TorkbusterTorsional Impactor, Liaoning Chemical Industry, 2012, 41(8):841-843

[5] J. W. Zheng, Y. H. Kuang, X. Wang, Z. Y. Zou, Y. Z. Chen and Y. X. Yang, Simulation study on he drilling of PDC bit at compound drilling condition (In Chinese), China Petroleum Machinery, 2016, 44(1):40-44.

[6] C. Q. Zha, G. H. Liu, J. Li, Y. Xi and T. Zhang, Analysis of torsional vibration characteristics of PDC bit and design of the damping tool (In Chinese), China Petroleum Machinery, 2017, 45(3):1-5.

[7] J. G. Xu, J. Yang, R. D. Tao and J. Chen, Self-excited oscillation rotary percussion drilling tools in dagang oilfield application (In Chinese), Drilling \& production technology, 2013, 36(3):124-125, 128

[8] H. S. Zhang, J. R. Ge, J. Yang, J. G. Yang, Z. Q. Li and L. L. Shi,. Effect evaluation of torsion impactor for increasing ROP in offshore deep formation, Fault-block oil \& gas field, 2014, 21(2):249-251.

[9] C. H. Fu, Z. Q. Chen, Y. He, D. F. Wei, K. Q. Liu and J. Hu, Structural design and performance analysis of novel torsional impact tool (In Chinese), China Petroleum Machinery, 2017, 45(11):7-12.

[10] C. Min, S. Z. Zhou, M. Q. Li and J. W. Li, Numerical simulation of internal flow field in hydraulic circumferential torque impact generator (In Chinese), China Petroleum Machinery, 2018, 46(1):1-6.
[11] H. H. Li, Y. X. WangandQ. J. Li, Experimental application of torque compactor in Well Zhaoshen17 inDaqing Oilfield, Exploration Engineering, 2013, 40(4):44-47.

[12] X. L. Yang, J. W. Song, S. M. He, X. L. Yu, T. Wang and L. Zhang, Evaluation of Parameters for Torsional Impact to Break Rock, Oil field equipmentil, 2014, 43(9):4-8.

[13] Q. Zhang, D. Li, W. Q. Jing and S. S. Hu, Research and Finite Element Analysis on Aggressive Single-cutter Placement of PDC Drill Bit, China Petroleum Machinery, 2014, 42(10):5-8.

[14] Z. Q. Huang, L. Tan, X. Jin, Q. Li and Z. Q. Wei, Simultion study on rock breaking mechanism of percussion rotary drill bit bass on 1s-dyna, Natural gas industry, 2007, 27(4):76-78.

[15] J. Zhang, PDC shock resistance and structural parameters optimization research, Wu Han: Wuhan University of Technology, 2012.

[16] W. Li, W. F. Sun, T. Yan, S. C. Chen and Y. Li, Field test of torsion impactorin well Jinyue 7-1 (In Chinese), China Petroleum Machinery, 2017, 45(3): 35-39.

[17] X. H. Dong and Y. T. Li, Application of consistent-WOB-torque drilling speed improving tool in well Xiahe 1, China Petroleum Machinery, 2017, 46(6):38-42.

[18] L. C. Xuan, Z. C. Guan, H. G. Hu and J. J. Li, Design and application of experimental apparatus for rock breaking by rotary percussion (In Chinese), Oil Drilling \& Production Technology, 2016, 38(1): 48-53.

[19] J. G. Xu, J. You, R. D. Tao, J. J. Wang, D. H. Lv and T. G. Fu, Applicationoftorkbuster in well yaxi102 of yumengollfield. Drilling \& production tech- nology, 2013, 36(4):37-39. 